1 Secretaria Municipal de Saúde (SMS) - Recife (PE), Brasil.

danielle.r.leal@terra.com.br

2 Secretaria Estadual de Saúde de Pernambuco (SES-PE), Secretaria Executiva de Vigilância em Saúde (Sevs) - Recife (PE), Brasil. Instituto de Medicina Integral Professor Fernando Figueira (Imip),

Grupo de Estudos de Gestão e Avaliação em Saúde (Geas) - Recife (PE) Brasil.

gcazarin@gmail.com

3 Secretaria Estadual de Saúde de Pernambuco (SES-PE), Secretaria Executiva de Vigilância em Saúde (Sevs) - Recife (PE), Brasil. Instituto de Medicina Integral Professor Fernando Figueira (Imip), Grupo de Estudos de Gestão e Avaliação em Saúde (Geas) - Recife (PE), Brasil.

lua_cad@yahoo.com.br

4 Instituto de Medicina Integral Professor Fernando Figueira (Imip), Grupo de Estudos de Gestão e Avaliação em Saúde (Geas) - Recife (PE), Brasil. ana_albuquerque1@hotmail. com

$\mathbf{5}$ Instituto de Medicina Integral Professor Fernando Figueira (Imip), Grupo de Estudos de Gestão e Avaliação em Saúde (Geas) - Recife (PE), Brasil. eronildo.felisberto@gmail. com

\section{Programa de Controle da Hanseníase: uma avaliação da implantação no nível distrital}

\author{
Leprosy Control Program: assessment of implementation in districts
}

Danielle Rodrigues Leal1, Gisele Cazarin², Luciana Caroline Albuquerque Bezerra³, Ana Coelho de Albuquerque $^{\mathbf{4}}$, Eronildo Felisberto 5

RESUMO Constitui objetivo deste estudo o de avaliar a implantação das ações do Programa de Controle da Hanseníase (PCH) em nível distrital no município de Recife, Pernambuco. Tratase de avaliação normativa, baseada em critérios e parâmetros orientados pela construção de um modelo lógico. O grau de implantação do PCH no distrito foi classificado como parcialmente adequado. Os critérios pior avaliados quanto à estrutura foram os recursos humanos e o espaço físico e quanto ao processo, o acolhimento, a educação permanente e a cogestão. A avaliação evidenciou que avanços ainda são necessários na descentralização das ações do PCH para o nível local.

PALAVRAS-CHAVE Avaliação em saúde. Hanseníase. Serviços de saúde.

ABSTRACT This study aimed at assessing the implementation of the actions predicted by the Control Program of Leprosy (CPL) in district level of the city of Recife, state of Pernambuco. It is a normative assessment based on criteria and parameters guided by the construction of a logic model. The CPL degree of implementation in the district was ranked as partially adequate as a whole. As for structure, human resources and premises were the worst assessed criteria, and when the process is concerned, user welcoming, permanent education and co-management received the worst assessments. The evaluation showed that improvements are still needed in the CPL decentralization to local level.

KEYWORDS Health evaluation. Leprosy. Health services. 


\section{Introdução}

Relacionada a condições desfavoráveis envolvendo fatores socioeconômicos e sanitários, como baixa renda familiar, baixa escolaridade e falta de condições básicas de saúde, a hanseníase é atualmente classificada pela Organização Mundial da Saúde (OMS) como uma doença negligenciada, prevalente em países em desenvolvimento. Essa classificação representa avanço na denominação 'doenças tropicais' por contemplar os contextos de desenvolvimento político, econômico e social, superando o determinismo meramente geográfico da causalidade das doenças. A maior parte das doenças negligenciadas é prevenível, uma vez que se dispõe de métodos eficazes de diagnóstico e tratamento (MAGALHÃES; ROJAS, 2007; MOREL, 2006; MOREL, 2011). Entretanto, a hanseníase é uma das doenças que continuam sendo um importante problema de saúde pública em várias regiões do mundo devido à sua magnitude, gravidade e relevância social.

Objetivando o redirecionamento das ações, o Brasil, seguindo a tendência mundial, assumiu, a partir de 2007, o objetivo de controlar e não mais erradicar a doença, instituindo os indicadores de detecção geral e detecção em menores de 15 anos para monitoramento e avaliação da endemia, enquanto o indicador de eliminação, baseado na prevalência, fica restrito à comparação com outros países e outros eventos de saúde pública no País (BRASIL, 2008; PERNAMBUCO, 2011).

O estado de Pernambuco se destaca em relação aos indicadores da doença. O coeficiente de detecção de casos novos em 2007 foi de 36/100.000, sendo considerado um dos maiores do País, quando comparado à média nacional no mesmo ano (21/100.000). Situação semelhante foi identificada em 2010, ocorrendo pequeno decréscimo nesse indicador para 31,78/100.000; para os menores de 15 anos, o indicador foi de 12,1 casos/100 mil habitantes, padrão de elevada magnitude. Em 2010, Pernambuco apresentou um padrão de média endemicidade segundo os parâmetros de prevalência, verificando-se áreas mais endêmicas concentradas a leste e a oeste de Pernambuco, próximo à área metropolitana e ao semiárido. Entre os 187 municípios do estado, 25 são considerados hiperendêmicos. A capital, Recife, apresentou 55,6 casos novos/100 mil habitantes em 2010, padrão muito alto de endemicidade, concentrando $40 \%$ dos casos novos registrados. Ao se avaliarem indicadores tais como a taxa de detecção anual de casos novos e em menores de 15 anos, o município foi classificado no extrato mais elevado (hiperendêmico), alcançando, respectivamente, $52,3 / 100.000$ e $21,3 / 100.000$ habitantes em 2010 (PERNAMBUCO, 2007; BRASIL, 2011; PERNAMBUCO, 2011).

No contexto epidemiológico de Recife, destaca-se a situação do Distrito Sanitário VI (DSVI). Em 2010, a situação epidemiológica evidenciava taxas de hiperendemicidade nos dois principais indicadores de monitoramento e avaliação adotados pela coordenação do Programa Nacional de Controle da Hanseníase (PNCH). A taxa de detecção de casos novos por 100.000 habitantes foi de 41,6, valor bem superior às taxas do estado de Pernambuco $(31,78)$ e do Brasil $(18,22)$ no mesmo ano. Já o coeficiente de detecção de casos novos em menores de 15 anos, atingiu 14,6 em 2010, bem superior ao coeficiente nacional $(5,36)$ e à da região nordeste $(8,46)$. O coeficiente obtido classifica a região como hiperendêmica, superando, inclusive, os índices da região norte, considerados os maiores do País. Enfatizando a magnitude e tendência crescentes da endemia no DSVI, temos que os coeficientes de detecção geral e detecção de casos novos em menores de 15 anos, no período 2000 a 2009 , vêm apresentando aumento gradual, indo de encontro à tendência nacional de redução (BRASIL, 2008; PERNAMBUCO, 2011).

Em tempo, cabe ressaltar que a Secretaria 
de Vigilância em Saúde do Ministério da Saúde, no início do ano de 2011, criou a Coordenação-Geral de Hanseníase e Doenças em Eliminação (CGHDE) com o objetivo de fortalecer a resposta para um grupo de doenças em que os resultados dos programas nacionais foram considerados insuficientes e incompatíveis com a capacidade do Sistema Único de Saúde (SUS) de resolução dos problemas de saúde da população. Nesse grupo, foram incluídas a hanseníase, esquistossomose, filariose linfática, geohelmintíases, oncocercose e tracoma. Essa mudança representou não só uma alteração organizacional, mas uma transformação na estratégia de abordagem que parte da integração das atividades voltadas ao conjunto de enfermidades com potencial de eliminação enquanto problema de saúde pública ou de redução drástica da carga dessas doenças (BRASIL, 2012).

A adoção da Estratégia Saúde da Família (ESF) como modelo de atenção básica à saúde promoveu o redirecionamento das prioridades em saúde, dentre elas a do controle da hanseníase. Além da implantação gradual da poliquimioterapia, a descentralização administrativa e de controle do Programa foi realizada à medida que passou a integrar as políticas relacionadas à atenção básica em saúde (BRASIL, 2008; BRASIL, 2009). Estrategicamente, o PNCH enfatiza cinco eixos estruturantes, a saber: 1) vigilância epidemiológica; 2) gestão com foco na descentralização, no planejamento, no monitoramento e na avaliação; 3) atenção integral; 4) comunicação e educação e; 5) desenvolvimento de pesquisas (ANDRADE ET AL., 2006; MOREIRA, 2002).

No município do Recife, o PNCH foi incorporado à atenção básica, tendo a gestão local distrital autonomia na condução dos processos e ações de acordo com a realidade territorial. No entanto, os eixos e diretrizes centrais seguem um modelo único de macro-política municipal (BRASIL, 1998; BRASIL, 2003). O fortalecimento da descentralização das ações no DSVI teve início em 2001. Anteriormente, os usuários portadores da doença eram atendidos nos distritos adjacentes. No ano seguinte, foi instalada a primeira unidade de referência de média complexidade para tratamento de hanseníase para garantir a atenção especializada sempre que necessário, além de assegurar o diagnóstico diferencial e o tratamento das complicações (PERNAMBUCO, 2011). A partir de 2004, teve início a implantação do Programa de Controle da Hanseníase Distrital (PCHD) junto às Equipes de Saúde da Família (EqSF).

Estudos sobre a implantação das ações de controle da hanseníase e o desempenho da atenção básica, muitas vezes, privilegiam as Unidades de Saúde da Família (USF) como foco de observação. Nesse sentido, é insuficiente o número de trabalhos que abordam o grau de implantação das ações do ponto de vista da gestão local como unidade de análise. Esse último enfoque constitui o objetivo central deste estudo, qual seja o de abordar o grau de implantação das ações de controle da hanseníase em nível local, ressaltando, além das atividades do programa, os dispositivos de gestão: acolhimento, clínica ampliada, cogestão, matriciamento e elaboração de Projetos Terapêuticos Singulares (PTS).

\section{Métodos}

Trata-se de um estudo avaliativo, do tipo normativo, em suas dimensões de estrutura e processo, com vistas à medição do grau de implantação da intervenção $\mathrm{PNCH}$ no DSVI do município do Recife, sede da região metropolitana do estado de Pernambuco. A avaliação do tipo normativa consiste em fazer um julgamento sobre uma intervenção, comparando os recursos empregados e sua organização (estrutura), os serviços ou bens produzidos (processo) e os resultados obtidos, com critérios e normas existentes 
(FIGUEIRÓ; FRIAS; NAVARRO, 2010). Essa tipologia comporta dois grandes desafios, os quais dizem respeito à força do vínculo causal postulado entre as estruturas, processos e resultados e à escolha das normas e critérios adequados. A validade das conclusões de uma avaliação normativa se relaciona diretamente com a pertinência e a exatidão das normas e critérios selecionados (CHAMPAGNE ET AL, 2011). O município apresenta uma população de aproximadamente 1.500 .000 habitantes, segundo o Censo de 2010 do Instituto Brasileiro de Geografia e Estatística (IBGE), distribuída em 94 bairros. A área territorial corresponde a $218 \mathrm{~km} 2$, na qual $70 \%$ da população vive em situação de pobreza com precárias condições de vida e elevada desigualdade social (PERNAMBUCO, 2011). A Secretaria Municipal de Saúde (SMS) tem o apoio de seis Distritos Sanitários o quais correspondem à divisão do município em Regiões Político-Administrativas (RPA). Além do quadro epidemiológico de destaque no que diz respeito à hanseníase, a seleção do DSVI como unidade de análise foi consequência do fato de apresentar o maior índice populacional do município e boa cobertura de atenção básica (64\%) (MARZLIAK ET AL., 2008).

A rede de atenção básica do DSVI está distribuída em oito bairros e dividida em três microregiões. Atualmente, conta com 77 EqSF instaladas em 32 USF, nove equipes de Programa Agentes Comunitários de Saúde (Pacs), além de seis Unidades Básicas Tradicionais. Outros equipamentos de saúde são agregados ao território de modo a compor a rede de atenção básica ampliada e de apoio. Dentre tais equipamentos, listam-se a Unidade Básica Tradicional, Residências Terapêuticas, Centros de Atenção Psicossocial, Policlínica, Maternidade, Farmácia da Família, Núcleo de Apoio à Saúde da Família, Programa Academia da Cidade. As Unidades de Referência (UR) do Programa são uma Policlínica e uma Unidade Básica Tradicional que, em conjunto com as USF, compõem a rede de atenção integrada aos casos de hanseníase.

Foram entrevistados profissionais de três níveis com o propósito de se observar a gestão e a integralidade do cuidado: 1) Nível Distrital (ND); 2) EqSF e 3) UR. Quanto à sede do DS, realizaram-se entrevistas com o coordenador e um técnico da vigilância epidemiológica responsável pelo acompanhamento desse agravo. No que se refere às EqSF, foram entrevistados profissionais da equipe básica: médico, enfermeiro, técnico de enfermagem, além de um Agente Comunitário de Saúde (ACS) por equipe. Este último foi selecionado de acordo com sua inserção em micro-área com maior número de casos novos da doença no ano de 2010. Na ocorrência de empate, optou-se pelo sorteio do ACS participante. Nas UR, foram entrevistados os profissionais da equipe multidisciplinar composta pelo médico, enfermeiro, fisioterapeuta e técnicos de enfermagem. A coleta de dados foi realizada no período de dezembro de 2010 a junho de 2011.

A avaliação teve caráter censitário ao abranger a totalidade das EqSF, as duas UR do DS, bem como todos os profissionais envolvidos com o PCHD, excetuando-se aqueles que se recusaram a participar da pesquisa, que estavam de férias, em algum tipo de licença, ausentes do local de trabalho no momento da pesquisa e aqueles profissionais que afirmaram não ser responsáveis pela realização do cuidado dos pacientes com hanseníase. Não foram incluídas no estudo as EqSF com período de implantação inferior a seis meses, o que totalizou uma amostra composta por $68 \mathrm{EqSF}$. Ao final, o universo do estudo foi de 184 profissionais.

Uma das estratégias empregadas para descrição de uma intervenção é a sua modelagem, dado que possibilita a representação configuracional da funcionalidade do programa por meio de uma síntese de seus principais componentes e da forma 
de operacionalização desses componentes (BEZERRA ET AL., 2009). O modelo lógico no âmbito distrital justifica-se, também, pelo fato de o PNCH utilizar como norteador apenas o instrumento de avaliação nacional, que, embora sendo importante, não atende às necessidades atuais para definição de medidas de intervenção para a redução da doença, bem como não considera o contexto loco-regional municipal. O modelo lógico preliminar foi submetido a quatro especialistas em doenças endêmicas e atores envolvidos com o PCHD, visto que aprimoram o modelo por meio da complementação das informações e da verificação da sua coerência interna (quadro 1).

Quadro 1. Modelo lógico do Programa de Controle da Hanseníase Distrital. Recife (PE), 2011

\begin{tabular}{|c|c|c|c|c|c|}
\hline Componente & Recursos & $\begin{array}{c}\text { Sub- } \\
\text { componentes }\end{array}$ & Atividades & Resultados intermediários & $\begin{array}{c}\text { Resultado } \\
\text { final }\end{array}$ \\
\hline Gestão & $\begin{array}{l}\text { RH } \\
\text { Veículos } \\
\text { Equipamentos } \\
\text { Insumos } \\
\text { Material de } \\
\text { expediente } \\
\text { Normas e } \\
\text { normatização } \\
\text { Espaço físico }\end{array}$ & $\begin{array}{l}\text { Educação } \\
\text { permanente e } \\
\text { cogestão }\end{array}$ & $\begin{array}{l}\text { - Realização de planejamento das ações do } \\
\text { PCHD em consonância com a coordenação } \\
\text { - Definição de indicadores para monitorar a situ- } \\
\text { ação da hanseníase no Distrito Sanitário. } \\
\text { - Realização de monitoramento, acompanha- } \\
\text { mento, e avaliação do plano distrital. } \\
\text { - Elaboração e implementação de protocolo de } \\
\text { atendimento e acesso à rede de saúde. } \\
\text { - Pactuação e discussão dos indicadores do } \\
\text { PCHD em conjunto com as equipes de saúde. } \\
\text { - Implantação da dose individualizada (DI) nas } \\
\text { unidades de saúde. } \\
\text { - Realização de ações integradas entre as ações } \\
\text { de assistência e vigilância à saúde. } \\
\text { ma de informação. } \\
\text { - Promoção de fórum micro- regional para dis- } \\
\text { cussão sobre o PCHD com os atores envolvidos. } \\
\text { - Perapêuticos Singulares. } \\
\text { - Discussão dos indicadores com as instâncias } \\
\text { de participação social (conselhos distritais, de } \\
\text { unidades, reuniões de microrregional). } \\
\text { - Pactuação de cronograma de atividades de } \\
\text { - de saúde. } \\
\text { - }\end{array}$ & $\begin{array}{l}\text { Descentralização das ações } \\
\text { para a rede de saúde. } \\
\text { Monitoramento e avaliação } \\
\text { realizados de acordo com o } \\
\text { Plano distrital. } \\
\text { Melhoria da qualidade da } \\
\text { atenção à saúde dos pa- } \\
\text { cientes. } \\
\text { Aumento da satisfação dos } \\
\text { usuários com a atenção à } \\
\text { saúde prestada. }\end{array}$ & 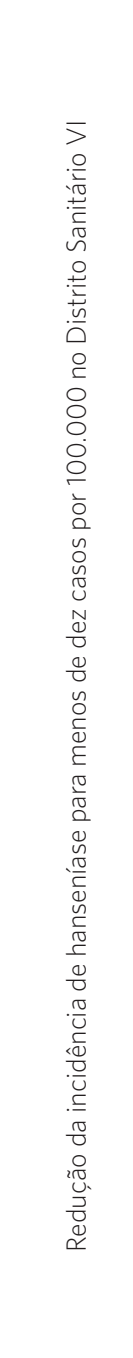 \\
\hline
\end{tabular}




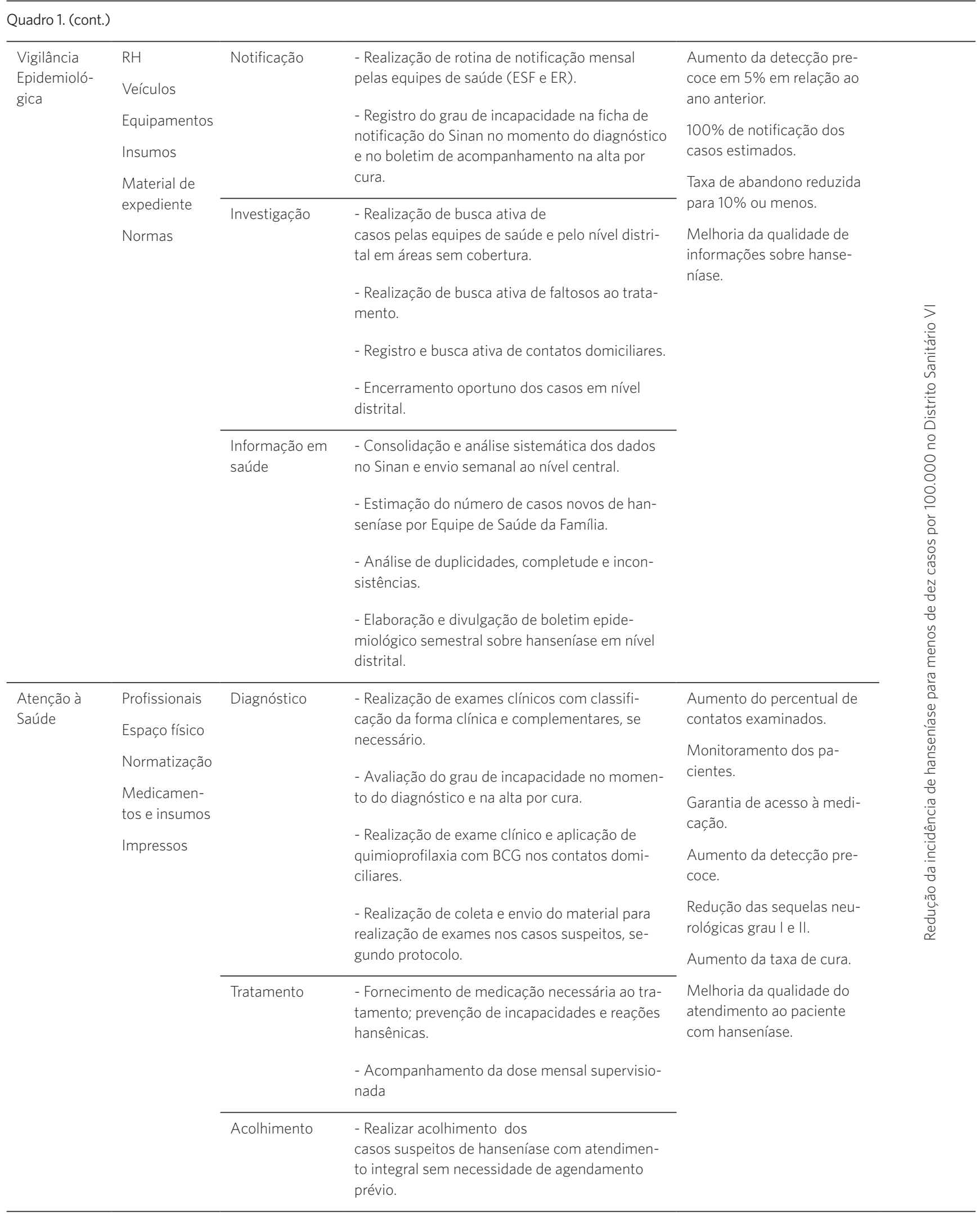


Quadro 1. (cont.)

\begin{tabular}{|c|c|c|c|c|c|}
\hline $\begin{array}{l}\text { Atenção à } \\
\text { Saúde }\end{array}$ & $\begin{array}{l}\text { Profissionais } \\
\text { Espaço físico } \\
\text { Normatização } \\
\text { Medicamen- } \\
\text { tos e insumos } \\
\text { Impressos }\end{array}$ & $\begin{array}{l}\text { Educação } \\
\text { permanente e } \\
\text { cogestão }\end{array}$ & $\begin{array}{l}\text { - Instituição de protocolo de referência e contrar- } \\
\text { referência. } \\
\text { - Organização do acesso e do fluxo entre ESF } \\
\text { e unidades de referência para atendimento às } \\
\text { intercorrências e sequelas. } \\
\text { - Realização de acompanhamento em conjunto } \\
\text { com a unidade de referência conforme protocolo. } \\
\text { - Disponibilização de consultas por especialidade } \\
\text { de acordo com a demanda e complexidade dos } \\
\text { casos de hanseníase. } \\
\text { - Elaboração de PTS para usuários de hanseníase } \\
\text { com situação de maior vulnerabilidade e } \\
\text { necessidades especiais. } \\
\text { - Realização de matriciamento entre equipe } \\
\text { de referência e de apoio para os casos de } \\
\text { hanseníase. } \\
\text { - Identificação de pacientes diagnosticados nas } \\
\text { ER, residentes em áreas cobertas pelas ESF, para } \\
\text { acompanhamento conjunto. } \\
\text { - Acompanhamento de usuários com difícil } \\
\text { adesão em conjunto com profissionais de outros } \\
\text { equipamentos de saúde no território. }\end{array}$ & $\begin{array}{l}\text { Aumento do percentual de } \\
\text { contatos examinados. } \\
\text { Monitoramento dos pa- } \\
\text { cientes. } \\
\text { Garantia de acesso à medi- } \\
\text { cação. } \\
\text { Aumento da detecção pre- } \\
\text { coce. } \\
\text { Redução das sequelas neu- } \\
\text { rológicas grau I e ll. } \\
\text { Aumento da taxa de cura. } \\
\text { Melhoria da qualidade do } \\
\text { atendimento ao paciente } \\
\text { com hanseníase. }\end{array}$ & 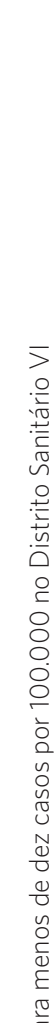 \\
\hline $\begin{array}{l}\text { Comunica- } \\
\text { ção e } \\
\text { Educação em } \\
\text { Saúde }\end{array}$ & $\begin{array}{l}\text { Profissionais } \\
\text { Materiais } \\
\text { educativos: } \\
\text { cartazes, } \\
\text { panfletos, } \\
\text { cartilhas, } \\
\text { CD-ROM, } \\
\text { vídeos, álbum } \\
\text { seriado. } \\
\text { Equipamen- } \\
\text { tos: DVD, TV }\end{array}$ & & $\begin{array}{l}\text { - Realização de ações educativas individuais e } \\
\text { coletivas mediante campanhas, palestras, visitas } \\
\text { domiciliares, atendimento individual, entre ou- } \\
\text { tros, sobre prevenção e controle da hanseníase. } \\
\text { - Realização de parcerias com escolas, ONGs, } \\
\text { igrejas e outros equipamentos sociais para } \\
\text { realização de ações educativas de controle da } \\
\text { hanseníase. } \\
\text { - Realização de parcerias intrassetoriais para } \\
\text { realização de ações educativas de controle da } \\
\text { hanseníase. } \\
\text { - Divulgação sobre prevenção da hanseníase em } \\
\text { meios de comunicação de massa: rádio comuni- } \\
\text { tária, televisão, jornal, entre outros. } \\
\text { - Fortalecimento da abordagem dos ACS nas } \\
\text { visitas domiciliares sobre a temática por meio } \\
\text { de discussões na unidade e reuniões técnicas da } \\
\text { equipe. }\end{array}$ & $\begin{array}{l}\text { Mudanças das práticas e } \\
\text { abordagens dos profissio- } \\
\text { nais. } \\
\text { Diminuição da estigmatiza- } \\
\text { ção da doença. } \\
\text { Aumento da informação } \\
\text { sobre o agravo na comu- } \\
\text { nidade. }\end{array}$ & 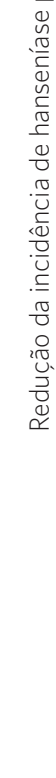 \\
\hline
\end{tabular}


Realizou-se a coleta de dados por meio de questionários semiestruturados, autoaplicados, elaborados especificamente para o estudo. Antes do trabalho de campo, os instrumentos foram analisados por especialistas da área técnica municipal e passaram por ajustes após a realização de pré-teste com dez entrevistados. Para fins de avaliação das dimensões de estrutura e processo, foram definidos os critérios e seus respectivos indicadores e parâmetros, pontuação esperada e peso de cada item de acordo com os componentes do modelo lógico por nível de análise (quadros 2,3 e 4). Atribuiu-se peso dois a algumas atividades e recursos essenciais para estruturação e consolidação do PCHD. A ponderação proposta foi submetida à apreciação de três especialistas para análise da coerência das pontuações. Em seguida, procedeu-se ao somatório dos pontos obtidos para cada critério a partir das respostas positivas, sendo multiplicados pelos pesos para cada indicador. A classificação final foi realizada considerando-se as dimensões de estrutura e processo para cada componente do modelo a partir dos três níveis de análise. O grau de implantação foi estimado mediante as pontuações obtidas a partir da seguinte fórmula:

Grau de Implantação:

$$
\mathrm{GI}=\frac{\sum \text { pontos observados }}{\sum \text { pontos esperados }} \times 100
$$

A classificação final do grau de implantação do PCHD foi determinada com base no somatório dos graus de implantação por nível de análise. Consideraram-se como pontos de corte para classificação do grau de implantação os seguintes parâmetros: adequado, de $100 \%$ a $80 \%$; parcialmente adequado, de $79,9 \%$ a $50 \%$ e incipiente, menor do que $50 \%$. As questões abertas do instrumento receberam tratamento descritivo e foram analisadas a partir da categorização das respostas.

Esta pesquisa foi aprovada pelo Comitê de Ética em Pesquisa do Instituto de Medicina Integral Professor Fernando Figueira (Imip), sob o $\mathrm{n}^{\circ}$ 2.192. Todos os participantes foram esclarecidos acerca dos objetivos da pesquisa e assinaram o Termo de Consentimento Livre e Esclarecido.

\begin{tabular}{|c|c|c|c|c|c|}
\hline $\begin{array}{l}\text { Dimensão e } \\
\text { componente }\end{array}$ & Critérios & Indicadores e parâmetros & $\begin{array}{l}\text { Peso de } \\
\text { cada } \\
\text { indicador }\end{array}$ & $\begin{array}{l}\text { № máximo } \\
\text { de respostas } \\
\text { por indicador }\end{array}$ & $\begin{array}{c}\text { Pontuação } \\
\text { máxima } \\
\text { esperada }\end{array}$ \\
\hline \multicolumn{6}{|c|}{ ESTRUTURA } \\
\hline & \multirow{3}{*}{$\begin{array}{l}\text { Recursos } \\
\text { humanos }\end{array}$} & - Coordenador distrital de hanseníase & 2 & 1 & 2 \\
\hline & & - Técnico em VE para hanseníase compartilhado com outras endemias & 2 & 1 & 2 \\
\hline & & - Pelo menos 2 técnicos de nível médio, sendo 1 do Sinan (VE e PCHD) & 1 & 1 & 2 \\
\hline & Espaço físico & - salas próprias para o PCHD e vigilância & 1 & 2 & 2 \\
\hline & \multirow{6}{*}{$\begin{array}{l}\text { Recursos } \\
\text { materiais }\end{array}$} & - Software do Sinan & 2 & 1 & 2 \\
\hline & & - № de veículos existents & 2 & 2 & 4 \\
\hline & & - № de computadores & 1 & 2 & 2 \\
\hline & & - № de impressoras & 1 & 2 & 2 \\
\hline & & - № de telefones & 1 & 2 & 2 \\
\hline & & - № de aparelhos de fax & 1 & 2 & 2 \\
\hline
\end{tabular}

Quadro 2. Matriz de medidas - Nível Distrital, Distrito Sanitário VI. Recife (PE), 2011 
Quadro 2. (cont.)

\begin{tabular}{|c|c|c|c|c|c|}
\hline & \multirow{10}{*}{$\begin{array}{l}\text { Impressos } \\
\text { e materiais } \\
\text { para ações } \\
\text { educativas }\end{array}$} & Material educativo & 2 & 2 & 4 \\
\hline & & - Ficha de Notificação (hanseníase) Sinan & 2 & 2 & 4 \\
\hline & & - Livro de Registro de Pacientes e Controle de Tratamento & 2 & 2 & 4 \\
\hline & & $\begin{array}{l}\text { - Protocolo complementar de investigação diagnóstica em menores de } 15 \\
\text { anos (PCID<15) }\end{array}$ & 2 & 2 & 4 \\
\hline & & - Boletim bimensal de acompanhamento de casos & 2 & 2 & 4 \\
\hline & & - Formulário de Vigilância de Contatos Intradomiciliares & 2 & 2 & 4 \\
\hline & & - Ficha B de acompanhamento de hanseníase (agente comunitário de saúde) & 2 & 2 & 4 \\
\hline & & - Cartão de cartão de aprazamento do paciente com hanseníase & 2 & 2 & 4 \\
\hline & & $\begin{array}{l}\text { - Formulário para avaliação do grau de incapacidade ou formulário para ava- } \\
\text { liação neurológica simplificada }\end{array}$ & 2 & 2 & 4 \\
\hline & & $\begin{array}{l}\text { - Ficha de investigação de suspeita de recidiva ou ficha de investigação de } \\
\text { intercorrência após alta por cura }\end{array}$ & 2 & 2 & 4 \\
\hline & \multirow{2}{*}{$\begin{array}{l}\text { Normas e } \\
\text { normatização }\end{array}$} & - Disponibilidade de regimento interno ou documento similar & 2 & 4 & 8 \\
\hline & & - Disponibilidade de normatizações técnicas quanto a diagnóstico e vigilância & 2 & 4 & 8 \\
\hline & \multirow{6}{*}{$\begin{array}{l}\text { Medicamen- } \\
\text { tos e insumos }\end{array}$} & - Poliquimioterapia esquema Paucibacilar /Multibacilar & 2 & 2 & 4 \\
\hline & & - Esquemas alternativos & 2 & 1 & 2 \\
\hline & & - Medicações para eventos reacionais & 2 & 1 & 2 \\
\hline & & - Vacina BCG & 2 & 1 & 2 \\
\hline & & - kit dermatoneurológico & 1 & 1 & 1 \\
\hline & & - Insumos para prevenção de incapacidade & 1 & 1 & 1 \\
\hline \multicolumn{6}{|c|}{ PROCESSO } \\
\hline \multirow[t]{9}{*}{ Gestão } & \multirow{3}{*}{$\begin{array}{l}\text { Planejamento } \\
\text { e acompa- } \\
\text { nhamento } \\
\text { na sede } \\
\text { do Distrito } \\
\text { Sanitário }\end{array}$} & - Planejamento anual entre PCHD e coordenação municipal & 2 & 1 & 2 \\
\hline & & - Monitoramento e acompanhamento do plano distrital trimestralmente & 2 & 1 & 2 \\
\hline & & - Pactuação e discussão dos indicadores com a equipe de saúde da família & 2 & 1 & 2 \\
\hline & \multirow{6}{*}{$\begin{array}{l}\text { Educação } \\
\text { permanente } \\
\text { e cogestão }\end{array}$} & - Ações da assistência com a vigilância sempre realizadas de maneira integral & 2 & 2 & 4 \\
\hline & & $\begin{array}{l}\text { - Apresentação anual ao Conselho Distrital de Saúde das ações de controle } \\
\text { da Hanseníase }\end{array}$ & 2 & 1 & 2 \\
\hline & & $\begin{array}{l}\text { - Envolvimento dos conselhos de unidades e conselho distrital nas ações de } \\
\text { divulgação }\end{array}$ & 2 & 1 & 2 \\
\hline & & $\begin{array}{l}\text { - Cronograma de atividades de matriciamento sobre o tema 'hanseníase' com } \\
\text { unidades de saúde }\end{array}$ & 2 & 1 & 2 \\
\hline & & $\begin{array}{l}\text { - Discussão de casos clínicos com alguma singularidade em conjunto com as } \\
\text { unidades de saúde (PTS) }\end{array}$ & 2 & 1 & 2 \\
\hline & & - 90\% dos profissionais do PCHD com formação nos últimos cinco anos & 2 & 1 & 2 \\
\hline \multirow{4}{*}{$\begin{array}{l}\text { Vigilância } \\
\text { Epidemioló- } \\
\text { gica }\end{array}$} & Notificação & - Rotina de notificação instituída com fluxo mensal & 2 & 1 & 2 \\
\hline & \multirow[t]{3}{*}{ Investigação } & - Realização de busca ativa sempre realizada & 2 & 1 & 2 \\
\hline & & - Realização de busca ativa dos casos de abandono sempre realizada & 2 & 1 & 2 \\
\hline & & - Realização de encerramento oportuno dos casos & 2 & 1 & 2 \\
\hline
\end{tabular}




\begin{tabular}{|c|c|c|c|c|c|}
\hline \multirow{2}{*}{$\begin{array}{l}\text { Vigilância } \\
\text { Epidemioló- } \\
\text { gica }\end{array}$} & \multirow[t]{2}{*}{$\begin{array}{l}\text { Informação } \\
\text { em saúde }\end{array}$} & $\begin{array}{l}\text { - Consolidação e análise dos dados mensalmente, incluindo análise de dupli- } \\
\text { cidade, completude e inconsistências }\end{array}$ & 2 & 2 & 4 \\
\hline & & $\begin{array}{l}\text { - Elaboração de um boletim semestral com análise dos indicadores de hanse- } \\
\text { níase em nível distrital }\end{array}$ & 2 & 2 & 4 \\
\hline $\begin{array}{l}\text { Comunicação } \\
\text { e Educação } \\
\text { em Saúde }\end{array}$ & $\begin{array}{l}\text { Comunicação } \\
\text { e Educação } \\
\text { em Saúde }\end{array}$ & $\begin{array}{l}\text { - Realização frequente de ações educativas em conjunto com as unidades de } \\
\text { saúde }\end{array}$ & 2 & 2 & 4 \\
\hline
\end{tabular}

Quadro 3. Matriz de medidas - Equipes de Saúde da Família, Distrito Sanitário VI. Recife (PE), 2011

\begin{tabular}{|c|c|c|c|c|c|}
\hline $\begin{array}{l}\text { Dimensão e } \\
\text { componente }\end{array}$ & Critérios & Indicadores e parâmetros & $\begin{array}{l}\text { Peso de } \\
\text { cada } \\
\text { indicador }\end{array}$ & $\begin{array}{l}\text { № máximo } \\
\text { de respostas } \\
\text { por indicador }\end{array}$ & $\begin{array}{c}\text { Pontuação } \\
\text { máxima } \\
\text { esperada }\end{array}$ \\
\hline \multicolumn{6}{|c|}{ ESTRUTURA } \\
\hline & $\begin{array}{l}\text { Recursos } \\
\text { humanos }\end{array}$ & $\begin{array}{l}\text { - Equipe de Saúde da Família completa (um médico, um enfermeiro, um técni- } \\
\text { co ou auxiliar de enfermagem e cinco ACS) }\end{array}$ & 2 & 68 & 136 \\
\hline & \multirow[t]{7}{*}{ Espaço físico } & - Número suficiente de consultórios & 2 & 107 & 214 \\
\hline & & - Tamanho adequado de consultórios & 1 & 107 & 107 \\
\hline & & - Iluminação adequada & 2 & 107 & 214 \\
\hline & & - Ventilação adequada & 2 & 107 & 214 \\
\hline & & - Espaço adequado para reunião da equipe & 2 & 107 & 214 \\
\hline & & - Espaços adequado para reuniões da equipe com a comunidade & 2 & 107 & 214 \\
\hline & & - Existência de privacidade & 2 & 107 & 214 \\
\hline & \multirow{10}{*}{$\begin{array}{l}\text { Impressos, } \\
\text { materiais } \\
\text { e equipa- } \\
\text { mentos para } \\
\text { ações educa- } \\
\text { tivas }\end{array}$} & - Material educativo, aparelho de DVD e televisão & 2 & 107 & 214 \\
\hline & & - Livro de Registro de Pacientes e Controle de Tratamento & 2 & 107 & 214 \\
\hline & & - Ficha de Notificação (hanseníase) Sinan & 2 & 107 & 214 \\
\hline & & $\begin{array}{l}\text { - Protocolo complementar de investigação diagnóstica em menores de } 15 \\
\text { anos (PCID<15) }\end{array}$ & 2 & 107 & 214 \\
\hline & & - Boletim de acompanhamento de casos bimensal & 2 & 107 & 214 \\
\hline & & - Formulário de Vigilância de Contatos Intradomiciliares & 2 & 107 & 214 \\
\hline & & - Ficha B de acompanhamento de hanseníase (ACS) & 2 & 107 & 214 \\
\hline & & - Cartão de cartão de aprazamento do paciente com hanseníase. & 2 & 107 & 214 \\
\hline & & $\begin{array}{l}\text { - Formulário para avaliação do grau de incapacidade ou formulário para ava- } \\
\text { liação neurológica simplificada }\end{array}$ & 2 & 214 & 428 \\
\hline & & $\begin{array}{l}\text { - Ficha de investigação de intercorrência após alta por cura ou ficha de inves- } \\
\text { tigação de suspeita de recidiva }\end{array}$ & 2 & 214 & 428 \\
\hline & $\begin{array}{l}\text { Normas e } \\
\text { normatização }\end{array}$ & - Disponibilidade de normas técnicas quanto ao diagnóstico e à vigilância & 2 & 107 & 214 \\
\hline & \multirow{2}{*}{$\begin{array}{l}\text { Medicamen- } \\
\text { tos e Insu- } \\
\text { mos }\end{array}$} & - Poliquimioterapia esquema Paucibacilar (PB) ou Multibacilar (MB) & 2 & 214 & 428 \\
\hline & & - Esquema alternativo & - & - & - \\
\hline
\end{tabular}


Quadro 3. (cont.)

\begin{tabular}{|c|c|c|c|c|c|}
\hline & \multirow{4}{*}{$\begin{array}{l}\text { Medicamen- } \\
\text { tos e Insu- } \\
\text { mos }\end{array}$} & - Medicações para eventos reacionais & 2 & 107 & 214 \\
\hline & & - Vacina BCG & 2 & 107 & 214 \\
\hline & & - Kit dermatoneurológico & 1 & 107 & 107 \\
\hline & & - Insumos para prevenção de incapacidade & 1 & 107 & 107 \\
\hline \multicolumn{6}{|c|}{ PROCESSO } \\
\hline \multirow[t]{5}{*}{ Gestão } & \multirow{5}{*}{$\begin{array}{l}\text { Educação } \\
\text { permanente } \\
\text { e cogestão }\end{array}$} & - Referência e contrarreferência instituídas entre ESF e unidades de referência & 2 & 107 & 214 \\
\hline & & $\begin{array}{l}\text { - Consultas por especialidade suficiente para o atendimento dos casos de } \\
\text { hanseníase mais complexos }\end{array}$ & 1 & 107 & 107 \\
\hline & & $\begin{array}{l}\text { - PTS realizados para pacientes com situação de maior vulnerabilidade e } \\
\text { necessidades especiais com a participação do ACS }\end{array}$ & 2 & 175 & 350 \\
\hline & & - Realização semestral de matriciamento sobre hanseníase & 2 & 175 & 350 \\
\hline & & $\begin{array}{l}\text { - 90\% dos profissionais que atuam em casos de hanseníase (médico, enfer- } \\
\text { meiro, e ACS) com formação nos últimos cinco anos }\end{array}$ & 2 & 175 & 350 \\
\hline \multirow{4}{*}{$\begin{array}{l}\text { Vigilância } \\
\text { Epidemioló- } \\
\text { gica }\end{array}$} & Notificação & Notificação de $100 \%$ dos casos de hanseníase & 2 & 107 & 214 \\
\hline & \multirow[t]{3}{*}{ Investigação } & -Realização de busca ativa sempre por médico, enfermeiro e ACS & 2 & 175 & 350 \\
\hline & & -Realização de busca ativa sempre por médico, enfermeiro e ACS & 2 & 175 & 350 \\
\hline & & $\begin{array}{l}\text {-Realização de busca ativa dos casos de abandono sempre por médico, enfer- } \\
\text { meiro e ACS }\end{array}$ & 2 & 175 & 350 \\
\hline \multirow{8}{*}{$\begin{array}{l}\text { Atenção à } \\
\text { saúde }\end{array}$} & \multirow[t]{5}{*}{ Diagnóstico } & -Identificação e encaminhamento de casos suspeitos & 2 & 68 & 136 \\
\hline & & - Pré-agendamento dos casos suspeitos & 1 & 68 & 68 \\
\hline & & - Priorização no atendimento & 2 & 68 & 136 \\
\hline & & $\begin{array}{l}\text { - Realização de exame clínico, classificação da forma clínica, solicitação de } \\
\text { exames quando necessário e avaliação do grau de incapacidade no momento } \\
\text { do diagnóstico e da cura }\end{array}$ & 2 & 749 & 1498 \\
\hline & & - Contatos examinados & 2 & 107 & 214 \\
\hline & \multirow[t]{2}{*}{ Tratamento } & $\begin{array}{l}\text {-Instituição e acompanhamento da dose mensal supervisionada, com consul- } \\
\text { tas de retorno pré-agendadas para profissionais de nível superior }\end{array}$ & 2 & 321 & 642 \\
\hline & & $\begin{array}{l}\text { - Visita mensal, realizando o acompanhamento do tratamento supervisionado } \\
\text { de todos os pacientes, incluindo os encaminhados para a Unidade de Referência }\end{array}$ & 2 & 204 & 408 \\
\hline & Acolhimento & $\begin{array}{l}\text {-Acolhimento funcionando por pelo menos cinco turnos nas unidades com a } \\
\text { participação do ACS }\end{array}$ & 2 & 175 & 350 \\
\hline $\begin{array}{l}\text { Comunicação } \\
\text { e educação } \\
\text { em saúde }\end{array}$ & $\begin{array}{l}\text { Comunicação } \\
\text { e educação } \\
\text { em saúde }\end{array}$ & $\begin{array}{l}\text { Realização de ações educativas com usuários e comunidade, pelo menos, } \\
\text { quinzenalmente }\end{array}$ & 2 & 175 & 350 \\
\hline
\end{tabular}

Quadro 4. Matriz de medidas - Unidades de Referência, Distrito Sanitário VI. Recife (PE), 2011

\begin{tabular}{|c|c|c|c|c|c|}
\hline $\begin{array}{l}\text { Dimensão e } \\
\text { componente }\end{array}$ & Critérios & Indicadores e parâmetros & $\begin{array}{c}\text { Peso de } \\
\text { cada } \\
\text { indicador }\end{array}$ & $\begin{array}{l}\text { № máximo } \\
\text { de respostas } \\
\text { por indicador }\end{array}$ & $\begin{array}{c}\text { Pontuação } \\
\text { máxima } \\
\text { esperada }\end{array}$ \\
\hline \multicolumn{6}{|c|}{ ESTRUTURA } \\
\hline \multirow{2}{*}{\multicolumn{2}{|c|}{$\begin{array}{l}\text { Recursos } \\
\text { humanos }\end{array}$}} & - Mínimo de três técnicos de nível superior & 2 & 2 & 4 \\
\hline & & - Mínimo de um técnico de nível médio & 1 & 2 & 2 \\
\hline
\end{tabular}


Quadro 4. (cont.)

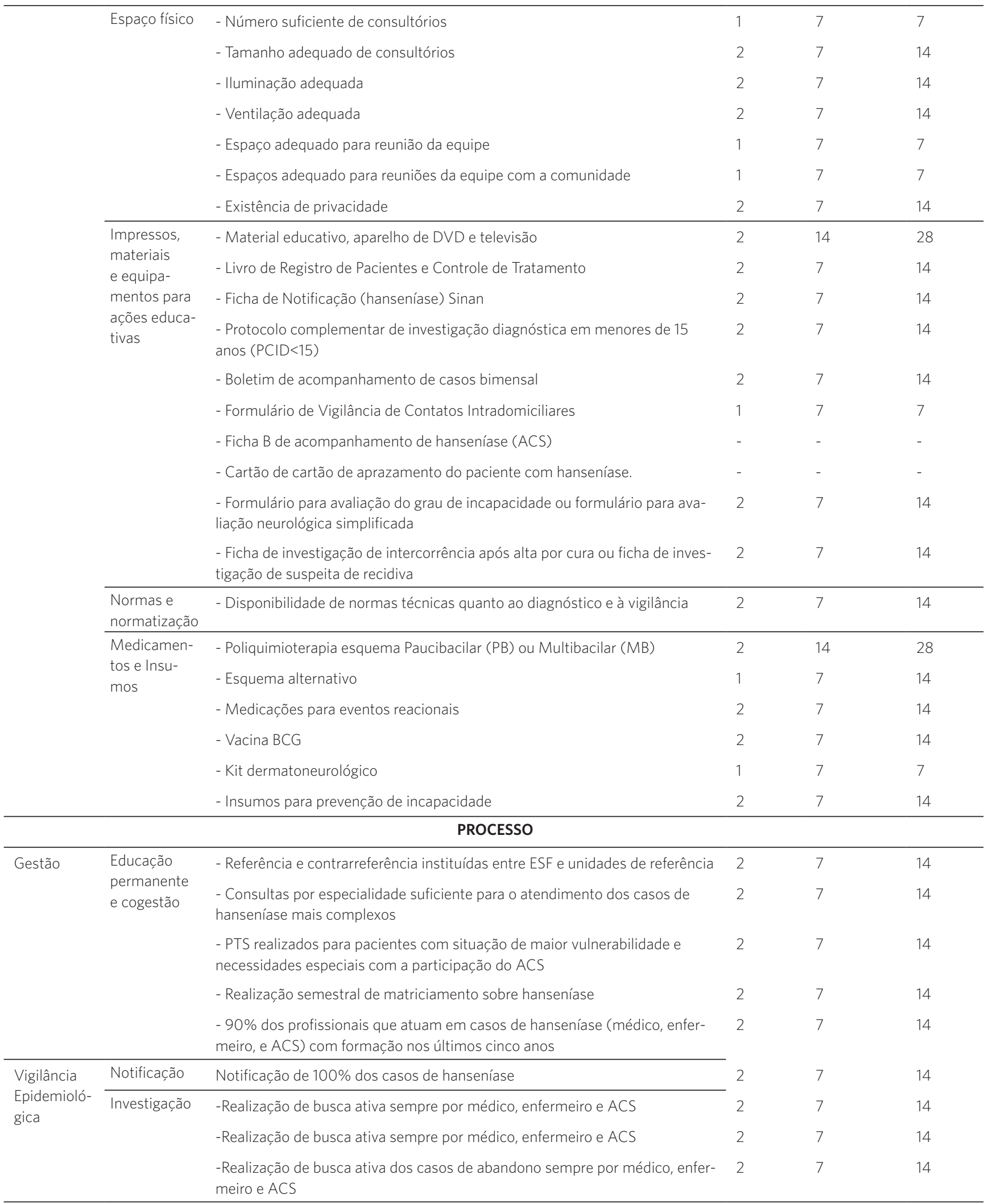




\begin{tabular}{|c|c|c|c|c|c|}
\hline \multirow[t]{4}{*}{$\begin{array}{l}\text { Atenção à } \\
\text { saúde }\end{array}$} & Diagnóstico & $\begin{array}{l}\text { - Realização de exame clínico, classificação da forma clínica, solicitação de } \\
\text { exames quando necessário e avaliação do grau de incapacidade no momento } \\
\text { do diagnóstico e da cura }\end{array}$ & 2 & 49 & 98 \\
\hline & & - Contatos examinados & 2 & 7 & 14 \\
\hline & Tratamento & $\begin{array}{l}\text {-Instituição e acompanhamento da dose mensal supervisionada, com consul- } \\
\text { tas de retorno pré-agendadas para profissionais de nível superior }\end{array}$ & 2 & 21 & 42 \\
\hline & Acolhimento & $\begin{array}{l}\text {-Acolhimento funcionando por pelo menos cinco turnos nas unidades com a } \\
\text { participação do ACS }\end{array}$ & 2 & 7 & 14 \\
\hline $\begin{array}{l}\text { Comunicação } \\
\text { e educação } \\
\text { em saúde }\end{array}$ & $\begin{array}{l}\text { Comunicação } \\
\text { e educação } \\
\text { em saúde }\end{array}$ & $\begin{array}{l}\text { Realização de ações educativas com usuários e comunidade, pelo menos, } \\
\text { quinzenalmente }\end{array}$ & 2 & 7 & 14 \\
\hline
\end{tabular}

\section{Resultados}

O grau de implantação do PCHD revelou-se parcialmente adequado. Avaliando-se os graus de implantação das dimensões de estrutura e processo observou-se que estes foram, no cômputo geral, semelhante ao do PCHD. A análise por nível apresentou grau de implantação diferenciado no nível distrital (adequado) quando comparado aos demais (parcialmente adequado). Os resultados da avaliação normativa são detalhados a seguir por dimensão, componentes do modelo lógico e critérios de avaliação, tomando-se por base os níveis de análise do estudo. Os resultados encontram-se consolidados no quadro 5.

Quadro 5. Matriz de resultados do grau de implantação do Programa de Controle da Hanseníase no Distrito Sanitário VI. Recife (PE), 2011

\begin{tabular}{|c|c|c|c|c|c|}
\hline Dimensão e componente & Critérios & $\begin{array}{l}\text { Nível distrital } \\
\quad n=2\end{array}$ & $E S F n=175$ & $E R n=7$ & TOTAL $n=184$ \\
\hline \multicolumn{6}{|c|}{ ESTRUTURA } \\
\hline \multirow{2}{*}{\multicolumn{2}{|c|}{ Recursos humanos }} & $02 / 06$ & $56 / 136$ & 04/06 & $63 / 152$ \\
\hline & & $33,33 \%$ & $41,76 \%$ & $66,6 \%$ & $41,45 \%$ \\
\hline \multirow{2}{*}{\multicolumn{2}{|c|}{ Espaço físico }} & $01 / 02$ & $694 / 1391$ & $33 / 77$ & $734 / 1499$ \\
\hline & & $50 \%$ & $49,89 \%$ & $42,85 \%$ & $48,97 \%$ \\
\hline \multirow{2}{*}{\multicolumn{2}{|c|}{ Recursos materiais }} & $8 / 12$ & - & - & $8 / 12$ \\
\hline & & $66,67 \%$ & - & - & $66,67 \%$ \\
\hline & \multirow{2}{*}{$\begin{array}{l}\text { Impressos, materiais, e equipamen- } \\
\text { tos para ações educativas }\end{array}$} & $36 / 60$ & $1295 / 2002$ & $87 / 119$ & $937 / 1485$ \\
\hline & & $90 \%$ & $64,68 \%$ & $73,11 \%$ & $63,10 \%$ \\
\hline & \multirow[t]{2}{*}{ Normas e normatização } & $6 / 6$ & $158 / 214$ & $14 / 14$ & $178 / 234$ \\
\hline & & $100 \%$ & $73,83 \%$ & $100 \%$ & $76,07 \%$ \\
\hline & \multirow[t]{2}{*}{ Medicamentos e insumos } & $18 / 18$ & $926 / 1062$ & $64 / 76$ & $996 / 1138$ \\
\hline & & $100 \%$ & $87,19 \%$ & $84,21 \%$ & $87,85 \%$ \\
\hline
\end{tabular}




\begin{tabular}{|c|c|c|c|c|c|}
\hline \multicolumn{2}{|l|}{ GI^ Estrutura } & $71 / 78$ & $3129 / 4805$ & $202 / 292$ & $3402 / 5175$ \\
\hline \multicolumn{6}{|c|}{ PROCESSO } \\
\hline \multirow[t]{6}{*}{ Gestão } & Planejamento e acompanhamento & $06 / 06$ & - & - & $06 / 06$ \\
\hline & & $100 \%$ & - & - & $100 \%$ \\
\hline & Educação permanente e cogestão & $12 / 14$ & $712 / 1337$ & $38 / 68$ & $761 / 1417$ \\
\hline & & $85,71 \%$ & $53,25 \%$ & $55,88 \%$ & $53,70 \%$ \\
\hline & TOTAL & & & & $767 / 1423$ \\
\hline & & & & & $53,90 \%$ \\
\hline \multirow{8}{*}{$\begin{array}{l}\text { Vigilância Epidemio- } \\
\text { lógica }\end{array}$} & Notificação & $2 / 2$ & $182 / 212$ & $8 / 14$ & $194 / 230$ \\
\hline & & $100 \%$ & $88,34 \%$ & $57,14 \%$ & $84,35 \%$ \\
\hline & Investigação & $06 / 06$ & $986 / 1072$ & $20 / 42$ & $1018 / 1126$ \\
\hline & & $100 \%$ & $91,97 \%$ & $47,61 \%$ & $90,41 \%$ \\
\hline & Informação em saúde & $8 / 8$ & - & - & $8 / 8$ \\
\hline & & $100 \%$ & - & - & $100 \%$ \\
\hline & TOTAL & & & & $1220 / 1364$ \\
\hline & & & & & $89,44 \%$ \\
\hline \multirow[t]{8}{*}{ Atenção à Saúde } & Diagnóstico & - & $1744 / 2128$ & $88 / 94$ & $1824 / 2212$ \\
\hline & & - & $81,95 \%$ & $93,61 \%$ & $82,46 \%$ \\
\hline & Tratamento & - & $866 / 1026$ & $32 / 38$ & $898 / 1064$ \\
\hline & & - & $84,40 \%$ & $84,21 \%$ & $84,4 \%$ \\
\hline & Acolhimento & - & $166 / 346$ & $6 / 14$ & $172 / 360$ \\
\hline & & - & $47,97 \%$ & $42,85 \%$ & $47,78 \%$ \\
\hline & TOTAL & & & & $2894 / 3636$ \\
\hline & & & & & $79,59 \%$ \\
\hline \multirow{2}{*}{$\begin{array}{l}\text { Comunicação e Educa- } \\
\text { ção em Saúde }\end{array}$} & & $0 / 4$ & $288 / 348$ & $8 / 14$ & $296 / 362$ \\
\hline & & $0 \%$ & $82,75 \%$ & $57,14 \%$ & $81,77 \%$ \\
\hline \multirow[t]{4}{*}{ Gl` Processo } & & $34 / 40$ & $4944 / 6469$ & $208 / 284$ & $5186 / 6793$ \\
\hline & & $85 \%$ & $76,42 \%$ & $73,24 \%$ & $76,34 \%$ \\
\hline & TOTAL & & & & $296 / 362$ \\
\hline & & & & & $81,77 \%$ \\
\hline \multirow[t]{2}{*}{$\mathrm{GI}^{\star}$ TOTAL } & & $105 / 118$ & $7596 / 10631$ & $410 / 576$ & $8097 / 11311$ \\
\hline & & $88,98 \%$ & $71,45 \%$ & $71,18 \%$ & $71,59 \%$ \\
\hline
\end{tabular}

*Grau de implantação:

Adequado: $100 \%$ a $80 \%$
Parcialmente adequado: $79,9 \%$ a $50 \%$
Incipiente: $49,9 \%$ e menos




\section{Dimensão 'estrutura'}

A avaliação da estrutura para as equipes de saúde (ESF e UR) foi realizada considerando-se cinco critérios: 1) recursos humanos; 2) espaço físico; 3) impressos, materiais e equipamentos para ações educativas; 4) normatização; 5) medicamentos e insumos. Para o ND, foram analisados, além dos cinco critérios acima, o de recursos materiais, que contempla a disponibilidade e adequação dos itens software do Sistema de Informação de Agravos de Notificação (Sinan), veículo, computadores, impressoras, telefones e aparelhos de fax.

Quando analisamos os critérios de estrutura em seu conjunto, verificamos um grau de implantação incipiente para recursos humanos e espaço físico, e apenas um critério classificado como adequado, para medicamentos e insumos. O critério de recursos humanos foi considerado insuficiente para atendimento da demanda em todos os níveis de análise. No ND, para o qual é preconizado que se tenha pelo menos um coordenador do PCHD, um técnico de nível superior na área de vigilância epidemiológica e dois técnicos de nível médio, havia apenas dois profissionais de nível superior que atuam de forma compartilhada entre o PCHD e outras ações programáticas da atenção básica.

Quanto às EqSF, verificou-se que apenas $41 \%$ delas apresentou conformidade com o parâmetro definido pela Portaria $\mathrm{n}^{\circ}$ 648/2006 (BRASIL, 2006). Nas UR, as condições de ventilação, espaço para reuniões de equipe e espaço para reunião com a comunidade obtiveram percentual abaixo de $50 \%$, enquanto nas EqSF, o indicador de ventilação foi um dos piores avaliados (7\%), seguido de condições de privacidade (21\%). Nesse âmbito, também, há ausência de espaços para reuniões com a comunidade e número de consultórios insuficientes, ambos com percentual de $43 \%$. No caso do
ND, não há disponibilidade de sala própria para o PCHD.

Os recursos materiais no ND obtiveram grau parcialmente adequado devido à inadequação e insuficiência de todos os itens avaliados: veículo, computadores, impressoras, telefones e aparelhos de fax. O critério 'impressos, materiais e equipamentos para ações educativas' apresentou GI parcialmente adequado, com exceção do ND, para o qual não foram incluídos os critérios de aparelho de DVD e televisão. A insuficiência de materiais e equipamentos para as ações educativas foi considerada por alguns entrevistados fator limitante ao fomento de práticas de educação em saúde. Destaca-se o número insuficiente de cartões de aprazamento dos pacientes (8\% para UR e $37 \%$ para EqSF), ficha de investigação de intercorrência após alta por cura (33\% para ambos) e formulário de vigilância de contatos domiciliares (43\% para UR e 49\% para EqSF).

Em relação à presença e disponibilidade de normas (parcialmente adequado), o resultado obtido revela a necessidade de readequação desse indicador nas EqSF, já que os guias de vigilância e assistência para os casos de hanseníase não estavam presentes para consulta em $25 \%$ dos consultórios analisados. No ND, chamou à atenção o fato de $100 \%$ dos entrevistados afirmarem que havia regimento interno ou documento similar definindo as atribuições do PCHD e disponibilidade dos guias de vigilância e assistência nos tres níveis analisados. Quanto ao critério 'medicamentos e insumos', o item mais bem pontuado, foi a disponibilidade e suficiência dos medicamentos para poliquimioterapia. Por outro lado, a disponibilidade de insumos para prevenção de incapacidades, como colírio e óleo mineral, foi considerada problemática pelos profissionais das EqSF (47\%). Em um dos serviços de referência, foi possível verificar, também, a ausência de vacina BCG. 


\section{Dimensão 'processo'}

A avaliação das atividades a serem desenvolvidas pelo PCHD foi realizada segundo os quatro componentes do modelo lógico e seus respectivos critérios: 1) gestão: planejamento e acompanhamento, educação permanente e cogestão; 2) vigilância epidemiológica: notificação, investigação e informação em saúde; 3) atenção à saúde: diagnóstico, tratamento e acolhimento; e 4) comunicação e educação em saúde. Na análise de cada um dos componentes, verificou-se que, no DS, a 'vigilância epidemiológica' foi o único que alcançou GI adequado. O componente 'gestão' encontra-se parcialmente adequado em razão do GI das atividades de educação permanente e cogestão. O componente 'atenção à saúde' (parcialmente adequado) obteve o pior resultado para as ações de acolhimento.

Ao se examinar o comportamento de cada um dos componentes por nível de análise, deve ser destacado que, no componente 'gestão', todos os entrevistados afirmaram realizar planejamento e acompanhamento das ações de controle da hanseníase no ND, muito embora admitissem haver dificuldades para integração entre as áreas técnicas do PCHD e vigilância. A educação permanente e cogestão, segundo os profissionais da rede de saúde (EqSF e UR), vêm sendo realizadas apenas parcialmente. As atividades pior avaliadas foram as de PTS (14\% para UR e 33\% para EqSF) e matriciamento ( $28 \%$ para UR e $29 \%$ para EqSF). Dentre os principais entraves mencionados há o descompasso entre a demanda e a oferta de serviços e a dificuldade de acesso a diversas especialidades, principalmente neurologistas e fisioterapeutas. No entanto, os profissionais das equipes de saúde reconheceram que a aplicação desses dispositivos aumenta a resolubilidade da atenção aos casos de hanseníase, na medida em que promove trocas e esclarecimento de dúvidas clínicas, principalmente para os casos mais complexos.
O estudo mostrou que o critério de referência e contrarreferência está instituído entre EqSF e UR (86\% para UR e 90\% para EqSF), embora os profissionais tenham afirmado que as consultas por especialidade são insuficientes para o atendimento de casos mais complexos. Ainda no que se refere a esse componente, outro fator que merece atenção refere-se ao investimento realizado nas atividades de formação: $100 \%$ e $86 \%$ dos profissionais de ND e UR, respectivamente, afirmaram ter realizado curso sobre hanseníase nos últimos cinco anos.

No componente 'vigilância epidemiológica', os resultados demonstraram que todos os critérios apresentaram GI adequado, com ressalva para as ações de notificação e investigação a partir das UR, sendo este último critério classificado como incipiente. Quanto ao critério de investigação, chama à atenção o fato de a busca ativa de casos de abandono do tratamento não ser uma atividade devidamente instituída segundo a maioria dos entrevistados (86\%), com ênfase nas UR, os quais alegam ser essa atividade de responsabilidade do ND, ou ainda, apontam a ausência de ACS.

A análise do componente de 'atenção à saúde' demonstrou GI em conformidade com o preconizado pelo $\mathrm{PNCH}$ nas atividades de diagnóstico e tratamento nos dois níveis analisados. Contribuem para esse resultado o baixo percentual de profissionais que não atendem casos de hanseníase (5\%) e o tempo de experiência no manejo de casos, pois mais de $50 \%$ afirmou trabalhar há mais de cinco anos com usuários acometidos pela doença. Em que pese o bom resultado obtido no critério 'diagnóstico', as avaliações do GI, tanto no momento do diagnóstico como na cura, receberam baixa pontuação pelos profissionais das EqSF, diferentemente do encontrado nas UR (adequado), nas quais pouco mais da metade afirmou realizar esses procedimentos (60\%). Ainda no que se refere a esse critério, observa-se percentual relativamente elevado de profissionais 
(72\%) que solicitam exames complementares para confirmação do diagnóstico.

O critério 'realização de exame clínico nos contatos' obteve elevados percentuais nos dois níveis de atuação estudados (85\% para UR e 96\% para EqSF). O acompanhamento da dose mensal supervisionada e o pré-agendamento das consultas foram classificados como adequado. $\mathrm{O}$ estudo revelou que cerca de $80 \%$ dos profissionais da rede de saúde apresentou boa apropriação das etapas de acompanhamento do tratamento supervisionado. Além disso, 90\% dos ACS afirmaram realizar supervisão sistemática do tratamento durante as visitas domiciliares e $92 \%$ destes acompanham os casos encaminhados para as UR.

É importante ressaltar que, apesar da incorporação do tratamento supervisionado na rotina das unidades de saúde, algumas dificuldades foram indicadas $(n=26)$ para sua implementação, tais como: (1) baixa adesão ao tratamento $(57,7 \%)$, principalmente de grupos vulneráveis - crianças e usuários de álcool e outras drogas; (2) pouco compromisso de alguns profissionais (26,9\%); e (3) número excessivo de usuários (7,7\%).

Quando questionados sobre a implantação do acolhimento e se este estava contribuindo para detecção de casos ou a resolubilidade da atenção, o percentual de respostas positivas foi baixo nos dois níveis de análise implicados (incipiente). A despeito disso, assinalou-se que o acolhimento se constitui em importante dispositivo para a melhoria da atenção à saúde, principalmente no que se refere à hanseníase. As justificativas mais frequentes para a não implantação do acolhimento foram, no caso das UR, a escassez de profissionais envolvidos e, nas EqSF, a restrição à quantidade de turnos preconizados (no mínimo cinco).

O GI do componente 'comunicação e educação em saúde’ foi adequado para o DS como um todo, embora tenha obtido classificações diversas para os níveis de análise. As pontuações obtidas pelo ND (0\%) e UR
(57\%) contrastaram com aquelas das EqSF (83\%). No caso das EqSF, verificou-se a consolidação das atividades de divulgação e educação em saúde com participação de todos os membros da equipe. Dentre as principais abordagens empregadas estão as atividades de grupo e orientação individual, adotadas com maior frequência pelos técnicos de nível superior e ACS, respectivamente. Os profissionais das EqSF informaram que há algumas dificuldades para a realização periódica das ações educativas. $\mathrm{Na}$ opinião dos ACS, isso se dá em razão do preconceito ainda existente quanto à doença, bem como pela escassez de material educativo. Os técnicos de nível superior, por sua vez, referiram quantidade insuficiente de material e equipamentos audiovisuais, seguida de grupos populacionais resistentes, como homens e alcoolistas, além de espaço físico inadequado para realização das atividades.

Quanto aos aspectos facilitadores à implementação das ações de controle da hanseníase, os profissionais alegaram a acessibilidade ao tratamento, seguida de equipe multidisciplinar com profissionais atualizados e interessados e da integração entre a equipe e a comunidade. Como entraves, observaram-se dificuldades de adesão ao tratamento, principalmente com presença de comorbidades, ausência de material educativo, ausência de formação, estigma, dificuldade de acesso à referência, espaço físico inadequado, sobrecarga de trabalho e dificuldade de realizar o diagnóstico.

\section{Discussão}

O processo de descentralização é fundamental na consolidação do SUS, sendo um de seus princípios organizativos. Entretanto, esse não é considerado um fim em si mesmo, à medida que por si só não garante a melhoria do desempenho do sistema de saúde (ANDRADE ET AL., 2006; HORTALE; PEDROZA; ROSA, 2000). 
Da mesma maneira, não se pode afirmar que a descentralização das ações do $\mathrm{PNCH}$ do nível federal para estados e municípios, e destes para as unidades básicas de saúde, seja a melhor estratégia para o controle da doença. No entanto, estudos revelam que esse processo vem contribuindo para o aumento da capacidade de diagnóstico, expresso pelo incremento no número de casos diagnosticados, em diferentes períodos da política de descentralização do $\mathrm{PNCH}$. Tais resultados são atribuídos a algumas das estratégias de fortalecimento das ações de controle da hanseníase para a rede básica de saúde, com destaque para apoio técnico e operacional e promoção de atividades de educação permanente (ANDRADE ET AL., 2006). Nesse aspecto, também é inegável que a ampliação da cobertura da ESF favoreceu o aumento no número de casos diagnosticados (ARANTES ET AL., 2010), ainda que, para os usuários acometidos pela hanseníase, a incorporação das ações venha se dando de maneira lenta, aquém do padrão de avanço do SUS (ANDRADE, 2006; ANDRADE ET AL., 2006).

Embora este estudo não tenha como objetivo avaliar a descentralização das ações do ponto de vista da autonomia política-organizacional e financeira, os resultados encontrados mostram a necessidade de investimentos nesse sentido. O GI do PCHD no DSVI foi considerado parcialmente adequado quando comparado às normas e metas preconizadas no nível nacional, com manutenção de indicadores que expressam a magnitude e relevância da doença. Estudos semelhantes realizados no estado do Mato Grosso (SPINELLI; IGNOTTI, 2007) e no município de Nova Iguaçu (RJ) (BRASIL, 2008), nos quais se avaliou a descentralização das ações de controle da hanseníase para a atenção básica, incluindo análise de contexto, revelaram, no geral, pouca influência do GI sobre os indicadores operacionais e de resultado definidos pelo $\mathrm{PNCH}$, além de insuficiente autonomia municipal.

Pesquisa realizada no município de
Camaragibe, Região Metropolitana do Recife, sobre avaliação da implantação das áreas estratégicas mínimas da atenção básica nas EqSF observou que as ações de eliminação da hanseníase estavam implantadas no Município (CAVAlCANTE ET AL., 2006). No entanto, concordando com os resultados do estudo do Mato Grosso, verificou-se discrepância entre os indicadores epidemiológicos e operacionais e o resultado obtido no GI, no qual foi observada situação hiperendêmica, com defasagem nos indicadores de proporção de cura dos casos novos e avaliação das incapacidades físicas no momento do diagnóstico e abandono do tratamento (CAVALCANTE ET AL., 2006; SPINELLI; IGNOTTI, 2007). Reiterando essa discussão, um estudo em Duque de Caxias (RJ) revelou a presença de grau II de incapacidade nos casos, configurando diagnóstico tardio, mesmo sendo um município com grau de descentralização adequado para as ações do Programa de Controle da Hanseníase (PCH) (CUNHA, 2007). Para Cavalcante e colaboradores (2006), em caso de desacordo entre os dados primários e secundários, é importante verificar possíveis incoerências e inconsistências na base de dados do Sinan, embora tais discrepâncias possam ser atribuídas ao fato de a hanseníase ser uma doença crônica, de evolução lenta, fazendo com que mudanças referentes à qualificação do programa somente apresentem influência em médio e longo prazos (SPINELLI; IGNOTTI, 2007).

\section{Conclusões}

Os resultados deste estudo sugerem a necessidade de aperfeiçoamento de quase todos os critérios eleitos. De fato, à exceção dos recursos humanos e espaço físico, que estão incluídos nas atribuições mais fortemente ligadas ao nível central, o restante dos critérios, classificados como parcialmente implantados, deveriam pertencer à governabilidade da gestão local, que é a responsável 
pelo seu provimento. Esse quadro demonstra a existência de dificuldades de autonomia técnico-gerencial e política, já que o bom desempenho administrativo não deve depender de recursos de custeio externo para as ações de assistência e manutenção da rede de saúde. Assim, em razão da avaliação aqui realizada, conclui-se que avanços ainda são necessários na descentralização das ações do PCH para o nível local.

\section{Referências}

ANDRADE, V. Implementação da PQT/OMS no Brasil. Hansenologia Internationalis, v. 31, n. 1, p. 23-31, 2006.

ANDRADE, V.; MOREIRA, T.; SOARES, R. C. F.

R. Impacto da descentralização do Programa de Eliminação da Hanseníase no Brasil. In: YADON, Z. E. et al. (Ed.). Descentralización y gestion del control de Las Enfermedades Transmisibles en América Latina. Buenos Aires, Argentina: OPS, 2006, p. 165-185.

ARANTES, C. et al. Avaliação dos serviços de saúde em relação ao diagnóstico precoce da hanseníase. Epidemiol. Serv. Saúde, Brasília, DF, v. 19, n. 2, p. 155164, abr./jun. 2010.

BEZERRA, L. C. A. et al. A vigilância epidemiológica no âmbito municipal: avaliação do grau de implantação das ações. Cad. Saúde Pública, Rio de Janeiro, v. 25, n. 4, p. 827-839, abr. 2009.

BRASIL. Ministério da Saúde. Portaria n ${ }^{\circ}$ 648, de 28 de março de 2006. Aprova a Política Nacional de Atenção Básica, estabelecendo a revisão de diretrizes e normas para a organização da Atenção Básica para o Programa Saúde da Família (PSF) e o Programa Agentes Comunitários de Saúde (PACS). Diário Oficial [da] União. Brasília, DF, 28 mar. 2006. Disponível em: <http://dab.saude.gov.br/docs/legislacao/ portaria_648_28_03_2006.pdf>. Acesso em: 18 out. 2016.
Ministério da Saúde. Secretaria de Assistência

à Saúde. Saúde da Família: uma estratégia para reorientação do modelo assistencial. 2. ed. Brasília, DF: Ministério da Saúde, 1998.

Ministério da Saúde. Secretaria de Atenção à Saúde. Departamento de Atenção Básica. Programa Saúde da Família: ampliando a cobertura para consolidar a mudança do modelo de Atenção Básica. Rev. brasil. saúde matern. Infan., Recife, v. 3, n. 1, p. 113125, jan./mar. 2003.

Ministério da Saúde. Secretaria de Vigilância em Saúde. Vigilância em Saúde: situação epidemiológica da Hanseníase no Brasil. Brasília, DF: Ministério da Saúde, 2008. Disponível em: <http://bvsms.saude.gov.br/bvs/ publicacoes/vigilancia_saude_situacao_hanseniase. pdf>. Acesso em: 18 out. 2016.

Ministério da Saúde. Secretaria de Vigilância em Saúde. Departamento de Vigilância em Doenças Transmissíveis. Plano integrado de ações estratégicas de eliminação da hanseníase, filariose, esquistossomose e oncocercose como problema de saúde pública, tracoma como causa de cegueira e controle das geohelmintíases: plano de ação 2011-2015. Série C. Projetos, Programas e Relatórios. Brasília, DF: Ministério da Saúde, 2012. Disponível em: <http://bvsms.saude. gov.br/bvs/publicacoes/plano_integrado_acoes_ estrategicas_2011_2015.pdf>. Acesso em: 18 out. 2016. 
Ministério da Saúde. Secretaria de Vigilância em Saúde. Departamento de Vigilância Epidemiológica. Relatório de gestão do Programa Nacional de Controle da Hanseníase - PNCH: maio de 2007 a dezembro de 2008. Série F. Comunicação e Educação em Saúde , Brasília, DF: Ministério da Saúde, 2009. Disponível em: $<$ http://www.mpdft.mp.br/saude/index.php/politicaspublicas/politicas-publicas-federal/163-coordenacaogeral-do-programa-nacional-de-controledahanseniase-cgpnch>. Acesso em: 19 jun. 2016.

Ministério da Saúde. Secretaria de Vigilância em Saúde. Sistema Nacional de vigilância em saúde. Relatório de situação: Pernambuco. 5. ed. Série C. Projetos, Programas e Relatórios, Brasília, DF: Ministério da Saúde, 2011. Disponível em: <http:// bvsms.saude.gov.br/bvs/publicacoes/sistema nacional_vigilancia_saude_pe_5ed.pdf $>$. Acesso em: 18 out. 2016.

CAVALCANTE, M. G. S. et al. Análise de implantação das áreas estratégicas da atenção básica nas equipes de Saúde da Família em município de uma Região Metropolitana do Nordeste brasileiro. Rev. bras. saúde matern. infant. Recife, v. 6, n. 4, p. 437- 445, out./dez. 2006.

CHAMPAGNE, F. et al. Apreciação Normativa. In: BROUSSELlE, A. et al. (Org.). Avaliação: Conceitos e Métodos. Rio de Janeiro: Fiocruz, 2011.

CUNHA, A. Z. S. Hanseníase: História de um problema de saúde pública. 2007. Tese. (Doutorado) Universidade de Santa Cruz do Sul, Santa Cruz do Sul, 2007.

\section{FIGUEIRÓ, A. C.; FRIAS, P. G.; NAVARRO, L. M.} Avaliação em saúde: conceitos básicos para a prática nas instituições. In: SAMICO, I. et al. (Org.). Avaliação em Saúde: Bases Conceituaise Operacionais. Rio de Janeiro: MedBook, 2010.

HORTALE, V. A.; PEDROZA, M.; ROSA, M. L. G. O acesso e a descentralização na análise de sistemas de saúde. Saúde debate, Rio de Janeiro, v. 24, n. 56, p. 5766, set./dez. 2000.
MAGALHÃES, M.; ROJAS, L. Diferenciação territorial da hanseníase no Brasil. Epidemiol. Servi. Saúde, Brasília, DF, v. 16, n. 2, p. 75-84, jun. 2007.

MARZLIAK, M. L. C. et al. Breve histórico sobre os rumos do controle da Hanseníase no Brasil e no Estado de São Paulo. Hansenol. Int., Bauru, v. 33, n. 2, supl. 1, p. 39-44. 2008

MOREIRA, T. M. A. Estudo de caso da avaliação da descentralização das ações programáticas de hanseníase. 2002. Tese. (Doutorado em Saúde Pública) - Escola Nacional de Saúde Pública, Fundação Oswaldo Cruz, Rio de Janeiro, 2002.

MOREL, C. Inovação em saúde e doenças negligenciadas. Cad. Saúde Pública, Rio de Janeiro, v. 22, n. 8, p. 1522-1523, ago. 2006.

O círculo infernal das chamadas doenças negligenciadas. Agência Fiocruz de Notícias. 2011. Disponível em: <https://agencia.fiocruz.br/artigodiscorre-sobre-o-c\%C3\%ADrculo-infernal-daschamadas-doen\%C3\%A7as-negligenciadas $>$. Acesso em: 18 out. 2016.

PERNAMBUCO. Secretaria Estadual de Saúde. Banco de dados da Vigilância à Saúde. Recife: Ministério da Saúde, 2011.

Secretaria Estadual de Saúde. Situação da hanseníase no estado de Pernambuco no período de 2001 a 2006. Pernambuco: Ministério da Saúde, 2007. Disponível em: <bvsms.saude.gov.br/bvs/publicacoes/ sistema_nacional_vigilancia_saude_pe_5ed.pdf $>$. Acesso em: 22 jun. 2016

SPINELLI, M. A.; IGNOTTI, E. Avaliação do programa de eliminação da hanseníase em Mato Grosso (20012003). Espaç. Saúde, Londrina, v. 9, n. 1, p. 25-35, dez. 2007.

Recebido para publicação em março de 2016

Versão final em outubro de 2016

Conflito de interesses: inexistente

Suporte financeiro: não houve 